\title{
Energy, exergy and environmental analyses of a combined cycle power plant under part-load conditions
}

\author{
Amin Mohammadi Khoshkar Vandani ${ }^{1}$, Mokhtar Bidi ${ }^{1}$ \\ and Mohammad Hossein Ahmadi ${ }^{2, a}$ \\ 1 Faculty of Mechanical and Energy Engineering, Shahid Beheshti University, Tehran, Iran \\ 2 Department of Renewable Energies, Faculty of New Sciences and Technologies, University of Tehran, Tehran, Iran
}

Received 5 January 2016, Accepted 14 March 2016

\begin{abstract}
The aim of this study is to evaluate the performance of combined cycle power plants in full and part-load operations in terms of energy, exergy and environment. The environmental analysis is performed using life cycle assessment method. Two different strategies are selected to control the gas turbine under part-load conditions, including Turbine Exhaust Temperature (TET) constant and Turbine Inlet Temperature (TIT) constant modes. Results show that gas turbine has a higher efficiency in TET constant mode. But, combined cycle shows a better efficiency in TIT constant mode. Exergy analysis results show that combustion chamber has the highest rate of exergy destruction, both in full and part-load operation. With reducing the load, total exergy destruction of the plant is decreased which is due to lower fuel consumption. Also reducing the load by $50 \%$ leads to $2.47 \%$ and $6.36 \%$ reduction in exergy efficiency of the plant in TIT and TET constant modes, respectively. Therefore, in terms of energy and exergy, it is suggested to use the TIT constant mode for part-load operation of the gas turbine within a combined cycle. But in terms of environmental analysis, results show that more emissions are produced in TIT constant mode, due to higher fuel consumption.
\end{abstract}

Key words: Energy / exergy / environmental analysis / life cycle analysis / combined cycle power plant / part-load

\section{Introduction}

Power generated in power plants should always adjust with electricity demand. Since electricity demand is fluctuating throughout a day, therefore sometimes the power plants have to operate under part-load conditions. As a result of part-load operation, efficiency of the plant is decreased. Therefore, it is important to perform necessary steps to prevent the efficiency reduction as much as possible. To do so, energy and exergy analyses could be very helpful. Between these two, second law is a better criterion than the first one. Since, beside energy transfer to the environment, it considers internal irreversibility of the system as well. Using exergy analysis, improvement potential of each component and the whole system could be identified.

Many authors performed exergy analysis on different types of energy systems. Ghorbani et al. [1] performed exergy analysis on a gas separation system and its refrigeration cycle. Tahmasebi et al. [2] analyzed a NGL

\footnotetext{
${ }^{a}$ Corresponding author:

mohammadhosein.ahmadi@gmail.com
}

recovery plant in terms of exergy. They considered five feeds with different percentages of composition. Ashouri et al. [3] studied a solar ORC system with different fluids ranging from high to low pressures and temperatures. Results show the suitability of benzene both with respect to thermodynamic and economic viewpoints. Ganjehsarabi et al. [4] carried out exergy and exergoeconomic analyses on a geothermal power plant. Their result showed that the plant's exergy efficiency equaled to $29.6 \%$. Also the highest exergy destruction cost was belonged to the cooling tower. Hajidavalloo et al. [5] performed energy and exergy analyses on a supercritical power plant and studied the effect of ambient temperature on energy and exergy efficiencies of the components. The results showed that exergy efficiency of the supercritical boiler is higher than a conventional one. Vandani et al. [6] proposed a heat recovery system for boiler blow down water in a steam power plant and optimized the plant in terms of exergy. Khanmohammadi et al. [7] analyzed a steam power plant in Iran based on exergy and exergoeconomic analyses and studied the effect of main steam temperature, reheated steam temperature, condenser pressure and number of 


\section{Nomenclature}

\begin{tabular}{|c|c|}
\hline$E x$ & Exergy $[\mathrm{kW}]$ \\
\hline$e x$ & Specific exergy $\left[\mathrm{kJ} . \mathrm{kg}^{-1}\right]$ \\
\hline$\overline{e x} \overline{c h}^{\text {ch }}$ & Standard chemical exergy $\left[\mathrm{kJ} . \mathrm{kmol}^{-1}\right]$ \\
\hline$\dot{E x}{ }^{\mathrm{D}}$ & Exergy destruction $[\mathrm{kW}]$ \\
\hline$\dot{E x}{ }^{Q}$ & Exergy associated to heat $[\mathrm{kW}]$ \\
\hline$\dot{E x} x^{\mathrm{w}}$ & Exergy associated to work $[\mathrm{kW}]$ \\
\hline$h$ & Enthalpy $\left[\mathrm{kJ} \mathrm{kg}^{-1}\right]$ \\
\hline$L H V$ & Lower heating value $\left[\mathrm{kJ} \cdot \mathrm{kg}^{-1}\right]$ \\
\hline$\dot{m}$ & Mass flow rate $\left[\mathrm{kg} \cdot \mathrm{s}^{-1}\right]$ \\
\hline$\dot{Q}$ & Heat $[\mathrm{kW}]$ \\
\hline$s$ & Entropy $\left[\mathrm{kJ}^{\mathrm{kg}} \mathrm{kg}^{-1} \cdot \mathrm{K}^{-1}\right]$ \\
\hline$T_{\mathrm{amb}}$ & Ambient temperature $[\mathrm{K}]$ \\
\hline$T$ & Temperature $[\mathrm{K}]$ \\
\hline$T_{\mathrm{p} z}$ & Adiabatic flame temperature $[\mathrm{K}]$ \\
\hline UHC & Unburned Hydrocarbon \\
\hline ORC & Organic Rankine Cycle \\
\hline HRSG & Heat Recovery Steam Generator \\
\hline$\dot{W}$ & Power $[\mathrm{kW}]$ \\
\hline$y$ & Mole fraction \\
\hline \multicolumn{2}{|r|}{ Greek letters } \\
\hline$\eta$ & Energy efficiency \\
\hline$\xi$ & chemical exergy/energy ratio \\
\hline$\tau$ & Residence time $[\mathrm{s}]$ \\
\hline$\psi$ & Exergy efficiency \\
\hline \multicolumn{2}{|r|}{ Subscript } \\
\hline $\mathrm{ch}$ & Chemical \\
\hline in & Inlet stream \\
\hline ke & Kinetic \\
\hline out & Outlet stream \\
\hline $\mathrm{ph}$ & Physical \\
\hline po & Potential \\
\hline
\end{tabular}

feed water heaters on the cycle performance and the final cost of electricity. They showed that increasing number of feed water heaters from zero to 6 could reduce the electricity price to half. Khaldi et al. [8] analyzed a gas turbine in Algeria in terms of exergy. The results showed that increasing the ambient temperature leads to an increase in exergy loss of the combustion chamber. Kim et al. [9] evaluated an exergy analysis for a combined cycle power plant which uses a low grade heat source and LNG cold energy. The combined cycle consists of a LNG power cycle and an ammonia-water Rankine cycle with and without regeneration. They calculated exergy destruction of each component along with total exergy efficiency of the plant. Ahmadi et al. [10] performed a multi-objective optimization on a combined cycle power plant, based on exergy, exergoeconomic and environmental analyses. Also the effect of supplementary firing was investigated. They showed that increasing the TIT leads to a decrease in the cost of exergy destruction of the power plant.

As mentioned before, part-load operation could considerably reduce the plant's efficiency. Yassi et al. [11] studied a specific kind of Kaplan hydro turbine in mi- cro scale. They installed a guide vane mechanism on the turbine and investigate the effect of this mechanism in full and part-load performance of the system. Mohamad et al. [12] studied the effect of two types of gasoline on performance and exhaust emissions in a spark ignition engine at various part-load conditions. Hosseinzadeh et al. [13] developed a model to investigate the exergy analysis of a dual fuel engine under part-load conditions. The exhaust gas recirculation is used to improve the performance of the engine. Roeder et al. [14] evaluated part-load behavior of a coal fired power plant equipped with a post combustion $\mathrm{CO}_{2}$ capture. The results showed that the post combustion $\mathrm{CO}_{2}$ capture could be shut downed to balance the generated power. A reduced capture rate of $75 \%$ leads to a generation of $5 \%$ additional power. Adibhatla et al. [15] investigated energy and exergy efficiencies of a supercritical coal fired power plant under $100 \%, 80 \%$ and $60 \%$ load and computed exergy destruction and exergy efficiency of each component. Also the effect of sliding pressure operation and constant pressure operation at part-loads were evaluated. The results showed that at part-load operation, due to reduced throttling losses, the sliding pressure has a better performance. Chan et al. [16] analyzed partload operation of a combined solid oxide fuel cell and gas turbine. Electrical and overall efficiencies of the system in full-load condition were $60 \%$ and $80 \%$, respectively, which is reduced in part-load operation. Also Bakalis et al. [17] performed an exergy analysis on a combination of micro gas turbine and solid oxide fuel cell at full and part-load conditions and calculated exergy destruction and exergy efficiency of each component. They utilized variable speed control strategy in part-load condition. Rachtan et al. [18] presented an expression to predict heat transfer rate of a heat recovery unit, which uses hot exhaust flue gas of a micro turbine at part-load conditions. The proposed model is a function of micro turbine power output, circulating water mass flow rate, and temperature of circulating water inlet. It was concluded that at low loads, variation of circulating water mass flow could not notably affect the heat transfer rate. Therefore, it is better to decrease the circulating water flow along with decreasing load. Malinowski et al. [19] studied part-load operation of a micro gas turbine using analytical approach. Using the obtained model, energy and exergy analyses were performed on a sample micro gas turbine. Wang et al. [20] studied part-load performance of a micro turbine which uses the concept of variable speed operation. They calculated the optimum speed variation for off-design performance using an analytical approach. The results showed that the variable speed operation has a better performance than constant speed operation and also the effect of temperature ratio on the efficiency is higher than the effect of pressure ratio. Kim et al. [21] performed an exergy analysis on the performance of a recuperated gas turbine under different part-load operation strategies for single shaft and two shaft configurations. The results showed that the fuel only control has the lowest efficiency among all. Also variable speed strategy led to a better performance of the system than the variable guide vane. This 


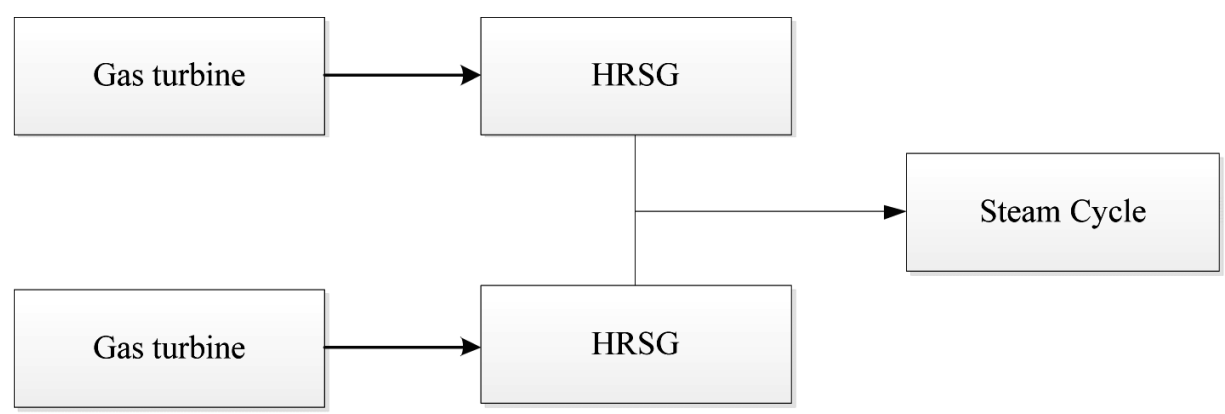

Fig. 1. General configuration of a combined cycle power block.

was due to fewer drops in the compressor efficiency. Also it was showed that a higher turbine inlet temperature and pressure ratio increases part-load efficiency of the system. Song et al. [22] carried out an exergy analysis on a heavy duty gas turbine with 150 MW output under part-load conditions. They discovered that exergy destruction in turbine stages caused by cooling air affects the overall efficiency of the turbine. De Escalona et al. [23] studied five different gas turbines coupled to an ORC bottoming cycle to achieve the highest overall efficiency in partload conditions. The results showed that a constant live vapor condition in the bottom cycle leads to maximum power generation. This could be used to compensate low efficiency of gas turbine in part-load conditions. Alobaid et al. [24] modeled a triple pressure combined cycle power plant in Aspen and Apros and compared the numerical results obtained by simulation programs with actual data in different part-load conditions and transient operation. Kim [25] compared design performance and part-load performance of gas turbines and combined cycle plants. Also, he investigated the effect of power control strategy on the part-load performance of the plant. The results showed that the gas turbines with higher design performances have higher part-load performances. Also with increasing turbine outlet temperature at fixed power, generated power in steam turbine increases. Using this way, total performance of the plant could be risen. Edris [26] studied single and multi-shaft gas turbines at part-load in terms of thermodynamic and environmental impact. The results showed that the single-shaft configuration is more suitable in terms of performance, $\mathrm{NO}_{x}$ specific emissions, $\mathrm{CO}_{2}$ specific emissions, start-up and extension possibilities. The multi-shaft configuration is more suitable with regards to space limitations, steam turbine shaft power, availability, and reliability.

In this study, energy, exergy and environmental analyses are performed on a combined cycle power plant at full and part-load operation and exergy destruction and exergy efficiency of each component and the whole plant is calculated. Two different strategies for operation of the gas turbine under part-load conditions are considered. These two strategies include a constant turbine inlet temperature (TIT constant) and a constant turbine outlet temperature (TET constant). Behavior of the bottom cycle (steam cycle) in each strategy is investigated. Also the two selected strategies are compared based on environmental analysis.
Table 1. Design specification of Siemens gas turbine.

\begin{tabular}{cc}
\hline Parameter & Value \\
\hline RPM & 3000 \\
Pressure Ratio & 11.1 \\
TIT $\left({ }^{\circ} \mathrm{C}\right)$ & 1149 \\
TET $\left({ }^{\circ} \mathrm{C}\right)$ & 540 \\
Air flow $\left(\mathrm{kg} . \mathrm{s}^{-1}\right)$ & 510 \\
LHV heat rate $\left(\mathrm{kJ} . \mathrm{Wh}^{-1}\right)$ & 10445 \\
LHV efficiency $(\%)$ & 34.5 \\
Output power $(\mathrm{MW})$ & 159 \\
\hline
\end{tabular}

\section{System description}

There are many configurations available for a combined cycle power plant. One of the most well-known configurations is shown in Figure 1 in which two gas turbines, two HRSGs and one steam turbine are coupled together. This configuration is referred to as $2 \times 2 \times 1$. This configuration is adapted because of economic reasons. Flue gas energy content of one gas turbine is not sufficient to produce the required steam for a steam turbine with capacity of the same order of the gas turbine; therefore, to overcome this issue two gas turbines are coupled together. In this configuration, there is an HRSG for each gas turbine. Total steam produced in the two HRSGs is used in the steam cycle.

Figure 2 shows the schematic of the combined cycle power plant with all its components. For simplicity, just one gas turbine and one HRSG are shown in this figure. The inlet air, after a compression process in the compressor, goes into the combustion chamber, where the combustion process occurs. Then, the hot flue gas is expanded in the turbine to generate power. The outlet stream of the gas turbine is still hot and its heat could be further used. To recover the energy of gas turbine outlet stream, a triple pressure HRSG is used. The high and intermediate pressure of produced steam in the HRSG is connected to the high and low pressure sections of steam turbine, respectively. Also the low pressure steam of the HRSG is fed to the deaerator. An air cooled condenser is used to condense steam and water mixture, after the steam turbine.

A 159 MW heavy-duty gas turbine, Siemens SGT52000 E model, was selected in this study. Design specification of this model is presented in Table 1 . 


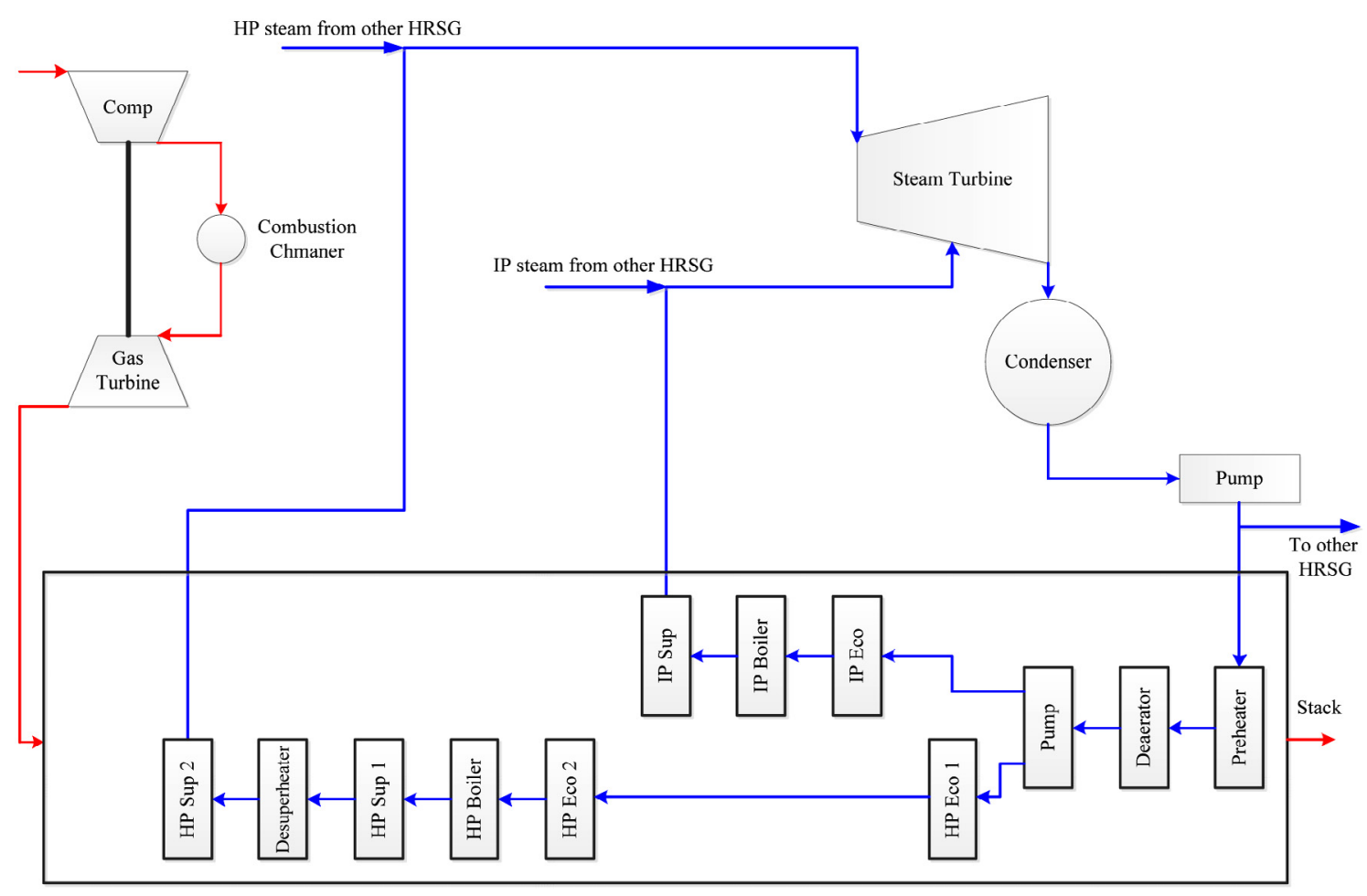

Fig. 2. Schematic of the combined cycle power plant.

Table 2. Fuel composition and properties.

\begin{tabular}{cc}
\hline Parameter & Value \\
\hline Molecular weight & 17.74 \\
LHV $\left[\mathrm{kJ.kg}^{-1}\right]$ & 46280 \\
Volumetric LHV $\left[\mathrm{kJ}^{-3}\right]$ & 33558 \\
Chemical composition (Volume percent) & \\
Hydrogen & 0.36 \\
Oxygen & 0.07 \\
Nitrogen & 3.65 \\
Carbon monoxide & 0.09 \\
Carbon dioxide & 0.34 \\
Methane & 87 \\
Ethane & 8.46 \\
Ethylene & 0.03 \\
\hline
\end{tabular}

Natural gas is used as fuel in the combustion chamber. Its volume percent and other properties are shown in Table 2.

\section{Exergy}

Exergy is the maximum work which can be obtained from a given form of energy using the environmental parameters as the reference state [27]. Exergy balance for a control volume is represented as:

$$
\dot{E x}{ }^{Q}+\sum \dot{m}_{i n} e x_{i n}=\dot{E} x^{w}+\sum \dot{m}_{\text {out }} e x_{\text {out }}+\dot{E} x^{D}
$$

In this equation $\dot{E x}{ }^{D}$ is the exergy destruction of the control volume and $\dot{E} x^{Q}$ and $\dot{E} x^{w}$ are the exergy associated with heat and work respectively and defined as follows $[28,29]$ :

$$
\begin{aligned}
& \dot{E x^{Q}}=\left(1-\frac{T_{0}}{T_{r}}\right) \dot{Q} \\
& \dot{E} x^{\mathrm{W}}=\dot{W}_{\text {c.v. }}
\end{aligned}
$$

where $T_{0}$ is the ambient temperature and $T_{r}$ is the temperature in which heat is transferred. Specific exergy is constituted of four components, including kinetic, potential, physical and chemical exergies.

$$
e x=e x_{\mathrm{ke}}+e x_{\mathrm{po}}+e x_{\mathrm{ph}}+e x_{\mathrm{ch}}
$$

Normally, the first two components are neglected due to small changes in speed and elevation [30]. To calculate the physical exergy, the following equation is used:

$$
e x_{\mathrm{ph}}=\left(h-h_{0}\right)-T_{0}\left(s-s_{0}\right)
$$

In this equation, " 0 " refers to the ambient situation. Also chemical exergy is defined as follows:

$$
e x_{\mathrm{ch}}=\sum_{i=1}^{N} y_{i} e x_{i}^{\mathrm{ch}}+R T_{0}\left(\sum_{i=1}^{N} y_{i} \ln \left(y_{i}\right)\right)
$$

Chemical exergy of the flue gas could be easily obtained using Equation (6). But to calculate the chemical exergy of fuel, it's a bit too complex. Therefore, the following expression is used to calculate the chemical exergy of fuels:

$$
x i=\frac{e x_{\text {fuel }}}{L H V_{\text {fuel }}}
$$


A.M. Khoshkar Vandani et al.: Mechanics \& Industry 17, 610 (2016)

Table 3. Exergy destruction and efficiency of each component in the plant.

\begin{tabular}{|c|c|c|}
\hline Component & Exergy destruction & Exergy efficiency \\
\hline Compressor & $\dot{E} x_{\mathrm{AC}}^{\mathrm{D}}=\dot{E} x_{\mathrm{in}}-\dot{E} x_{\mathrm{out}}+\dot{W}_{\mathrm{AC}}$ & $\psi_{\mathrm{AC}}=\frac{E x_{\mathrm{out}}-E x_{\mathrm{in}}}{\dot{W}_{\mathrm{AC}}}$ \\
\hline Combustion chamber & $\dot{E} x_{\mathrm{CC}}^{\mathrm{D}}=\dot{E} x_{\mathrm{in}}+\dot{E} x_{\mathrm{fuel}}-\dot{E} x_{\mathrm{out}}$ & $\psi_{\mathrm{CC}}=\frac{\stackrel{W \mathrm{AC}}{E x_{\text {out }}}}{E}$ \\
\hline Gas turbine & $\dot{E} x_{\mathrm{GT}}^{\mathrm{D}}=\dot{E} x_{\mathrm{in}}-\dot{E} x_{\mathrm{out}}-\dot{W}_{\mathrm{GT}}$ & $\begin{array}{l}\psi \mathrm{CC}-\overline{E x_{\mathrm{in}}+E x_{\mathrm{fuel}}} \\
\psi_{\mathrm{GT}}=\frac{\dot{W}_{\mathrm{GT}}}{E x_{\mathrm{in}}-E x_{\mathrm{out}}}\end{array}$ \\
\hline HRSG & $\dot{E} x_{\mathrm{HRSG}}^{\mathrm{D}}=\sum \dot{E} x_{\mathrm{in}}-\sum \dot{E} x_{\mathrm{out}}$ & $\psi_{\mathrm{HRSG}}=\frac{\dot{E x_{\text {steam }, \text { out }}-\dot{E} x_{\text {steam }, \text { in }}}}{E x_{\text {gas }, \text { out }}-E x_{\text {gas }, \text { in }}}$ \\
\hline Steam turbine & $\dot{E} x_{\mathrm{ST}}^{\mathrm{D}}=\dot{E} x_{\mathrm{in}}-\dot{E} x_{\mathrm{out}}-\dot{W}_{\mathrm{ST}}$ & $\psi_{\mathrm{ST}}=\frac{\dot{W}_{\mathrm{ST}}}{E x_{\mathrm{in}}-E x_{\mathrm{out}}}$ \\
\hline Condenser & $\dot{E} x_{\mathrm{Cond}}^{\mathrm{D}}=\sum \dot{E} x_{\mathrm{in}}-\sum \dot{E} x_{\mathrm{out}}$ & $\psi_{\text {Cond }}=1-\frac{E x_{\mathrm{D}, \text { Cond }}}{\sum E x_{\text {in }}}$ \\
\hline Pump & $\dot{E} x_{\mathrm{Pump}}^{\mathrm{D}}=\dot{E} x_{\mathrm{in}}-\dot{E} x_{\mathrm{out}}+\dot{W}_{\mathrm{Pump}}$ & $\psi_{\text {Pump }}=\frac{\dot{E} x_{\text {out }}-\dot{E} x_{\text {in }}}{\dot{W}_{\text {Pump }}}$ \\
\hline
\end{tabular}

For the most commonly fuel gases, the amount of $\xi$ is close to unity [30] For example, this value for methane and hydrogen is equal to 1.06 and 0.985 , respectively.

After performing the exergy analysis and calculating exergy of each stream, exergy destruction and efficiency of the components could be obtained using equations in Table 3 .

Also total exergy efficiency of the plant is defined as follows:

$$
\psi_{\text {total }}=\frac{\dot{W}_{\text {net }}}{\dot{m}_{\text {fuel }} \xi L H V}
$$

\section{Environmental analysis}

There are many approaches to perform the environmental analysis. Among them, life cycle assessment (LCA) is a comprehensive method which takes into account all the stages of a product's life, including its raw material extraction, manufacture, use and finally disposal. LCA is performed in 4 steps, including goal and scope, life cycle inventory (LCI), life cycle impact assessment (LCIA) and interpretation [31]. In this paper, eco-indicator 99 [32] is used to quantify the environmental impact of the process. In this technique, three types of environmental damages are considered: damage to human health, damage to ecosystem quality, depletion of resources. Each of these damages has some subcategories, e.g. carcinogenic effects on humans, respiratory effects, climate change, ozone layer depletion, acidification and eutrophication, etc.

Environmental impacts of a power plant could be classified into construction, operation and disposal phases. The construction and disposal phases are usually neglected, due to low amount of produced emission in these phases [33-35]. Environmental impacts of operation phase include producing air, water and soil contaminants. In this paper, only air pollutants are considered. These pollutants are assumed to be mainly carbon dioxide $\left(\mathrm{CO}_{2}\right)$, carbon monoxide $(\mathrm{CO}), \mathrm{NO}_{x}$ and Unburned Hydrocarbons (UHC). To perform the analysis, mass flow rate of each of these pollutants should be calculated and then multiplied to the corresponding indicator provided by the eco-indicator and then combined together to form a single score. The obtained score is used to compare the envi- ronmental effect of the power plant in different part-load conditions.

Mass flow rate of carbon dioxide is calculated based on the mole percent of the outlet flue gas. Other contaminants do not appear in the combustion reaction. The following empirical equations are used to calculate the mass flow rate of these pollutants [10]:

$$
\begin{aligned}
\dot{m}_{\mathrm{NO}_{x}} & =\frac{0.15 \times 10^{16} \times \tau^{0.5} \times \exp \left(-71100 / T_{\mathrm{Pz}}\right)}{P_{\text {inlet }}^{0.05} \times\left(\Delta P_{3} / P_{3}\right)^{0.5}} \\
\dot{m}_{\mathrm{CO}} & =\frac{0.179 \times 10^{9} \times \exp \left(7800 / T_{\mathrm{Pz}}\right)}{P_{\text {inlet }}^{2} \times \tau \times\left(\Delta P_{\text {inlet }} / P_{\text {inlet }}\right)^{0.5}} \\
\dot{m}_{\mathrm{UHC}} & =\frac{0.755 \times 10^{11} \times \exp \left(9756 / T_{\mathrm{Pz}}\right)}{P_{\text {inlet }}^{2.3} \times \tau^{0.1} \times\left(\Delta P_{\text {inlet }} / P_{\text {inlet }}\right)^{0.6}}
\end{aligned}
$$

In these equations, $\tau$ is the residence time and assumed to be equal to $0.002 \mathrm{~s}, P_{\text {inlet }}$ is the pressure of inlet stream to the combustor and $\Delta P_{\text {inlet }} / P_{\text {inlet }}$ is the dimensionless pressure drop in the combustion chamber. $T_{\mathrm{P} z}$ is the adiabatic flame temperature which could be obtained by Equation (12):

$$
T_{\mathrm{Pz}}=A \sigma^{\alpha} \exp \left(\beta(\sigma+\lambda)^{2}\right) \pi^{x} \theta^{y} \psi^{z}
$$

In Equation (12), $\pi$ and $\theta$ are $P / P_{\mathrm{amb}}$ and $T / T_{\mathrm{amb}}$, respectively. $\psi$ is the $\mathrm{H} / \mathrm{C}$ atomic ratio of the fuel and $\sigma$ is defined based on molar ratio $(\phi)$ as follows:

$$
\sigma=\left\{\begin{array}{l}
\phi, \phi<1 \\
\phi-0.7, \phi \geqslant 1
\end{array}\right.
$$

Also, $x, y$ and $z$ are a function of $\sigma$ and calculated as follows:

$$
\begin{aligned}
& x=a_{1}+b_{1} \sigma+c_{1} \sigma^{2} \\
& y=a_{2}+b_{2} \sigma+c_{2} \sigma^{2} \\
& z=a_{3}+b_{3} \sigma+c_{3} \sigma^{2}
\end{aligned}
$$

Also $A, \alpha, \beta, \lambda, a_{i}, b_{i}$ and $c_{i}$ are constants parameters shown in Table 4.

\section{Results and discussion}

In this section, results of energy and exergy analyses are presented. To do this, the plant was modeled in GT 
A.M. Khoshkar Vandani et al.: Mechanics \& Industry 17, 610 (2016)

Table 4. Constant parameters of Equation (12) to (16) [10].

\begin{tabular}{ccccc}
\hline \multirow{2}{*}{ Parameters } & \multicolumn{2}{c}{$0.3 \leq \varphi \leq 1.0$} & \multicolumn{2}{c}{$1.0 \leq \varphi \leq 1.6$} \\
\cline { 2 - 5 } & $0.92 \leq \theta \leq 2$ & $2 \leq \theta \leq 3.2$ & $0.92 \leq \theta \leq 2$ & $2 \leq \theta \leq 3.2$ \\
\hline $\mathrm{A}$ & 2361.76 & 2315.75 & 916.82 & 1246.17 \\
$\alpha$ & 0.1157 & -0.049 & 0.288 & 0.381 \\
$\beta$ & -0.948 & -1.114 & 0.145 & 0.347 \\
$\lambda$ & -1.097 & -1.18 & -3.277 & -2.0365 \\
$a_{1}$ & 0.014 & 0.01 & 0.031 & 0.036 \\
$b_{1}$ & -0.055 & -0.045 & -0.078 & -0.085 \\
$c_{1}$ & 0.052 & 0.0482 & 0.0497 & 0.0517 \\
$a_{2}$ & 0.395 & 0.568 & 0.025 & 0.009 \\
$b_{2}$ & -0.441 & -0.55 & 0.26 & 0.502 \\
$c_{2}$ & 0.141 & 0.132 & -0.131 & -0.247 \\
$a_{3}$ & 0.005 & 0.011 & 0.004 & 0.017 \\
$b_{3}$ & -0.129 & -0.129 & -0.178 & -0.189 \\
$c_{3}$ & 0.082 & 0.084 & 0.098 & 0.1037 \\
\hline
\end{tabular}

$\rightarrow$ TET const $\longrightarrow$ TIT const

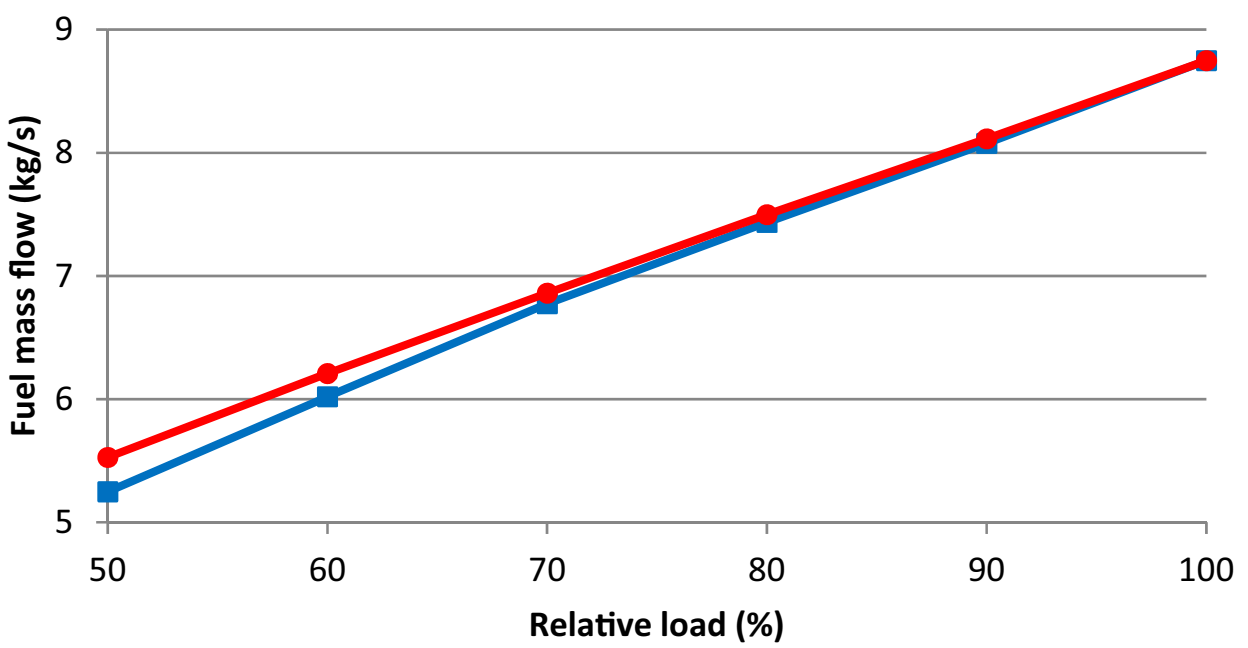

Fig. 3. Variation of fuel mass flow with relative load.

Pro software [36] and the thermodynamic properties of each stream, including temperature, pressure, enthalpy, entropy and mass flow rates were obtained. Then, these parameters were used in Matlab software to perform the exergy analysis.

When the electricity demand is reduced, the generated power of the plant should decrease. To do so, the air and fuel mass flow in the gas turbine reduces. Therefore, the power generated in the gas turbine is decreased. Also, as a result of air and fuel mass flow reduction, energy content of the gas turbine outlet flue gas is reduced and therefore lower steam is produced in the two HRSGs. With decreasing the produced steam in the HRSG, the pinch-point temperature difference will be a few degrees below that assumed in the full-load operation. This is because the HRSG surface area is fixed, but the heat transfer duty is decreased, resulting in a lower heat flux. The reduced heat transfer burden, per square meter of surface area, results in smaller terminal temperature differences. Therefore, performance of the plant is changed during the part-load operation.
As mentioned above, air and fuel mass flow rates are the two parameters that used to control the operation of gas turbines in part-load conditions. Changing these parameters results in different strategies in part-load operation of the gas turbine. The two well-known strategies are TET constant and TIT constant modes. In the first strategy, both air and fuel mass flow rates are decreased in a way that the turbine outlet temperature remains constant, while in the other strategy, turbine inlet temperature is kept constant and its value at part-load is equal to the design condition. These strategies are applied to the plant using GT Pro software.

To gain a better insight, variations of air and fuel mass flow rates of the gas turbine along with its inlet and outlet temperature with load variation in the two strategies are shown in Figures 3 to 6 . The relative load of the gas turbine is varied between $100 \%$ which is equal to full-load and $50 \%$. The part-load operation of below $50 \%$ is not considered in this study, because it is hardly happen that a power plant operates in a load lower than $50 \%$, due to thermal stresses in the components and economic reasons. 
A.M. Khoshkar Vandani et al.: Mechanics \& Industry 17, 610 (2016)

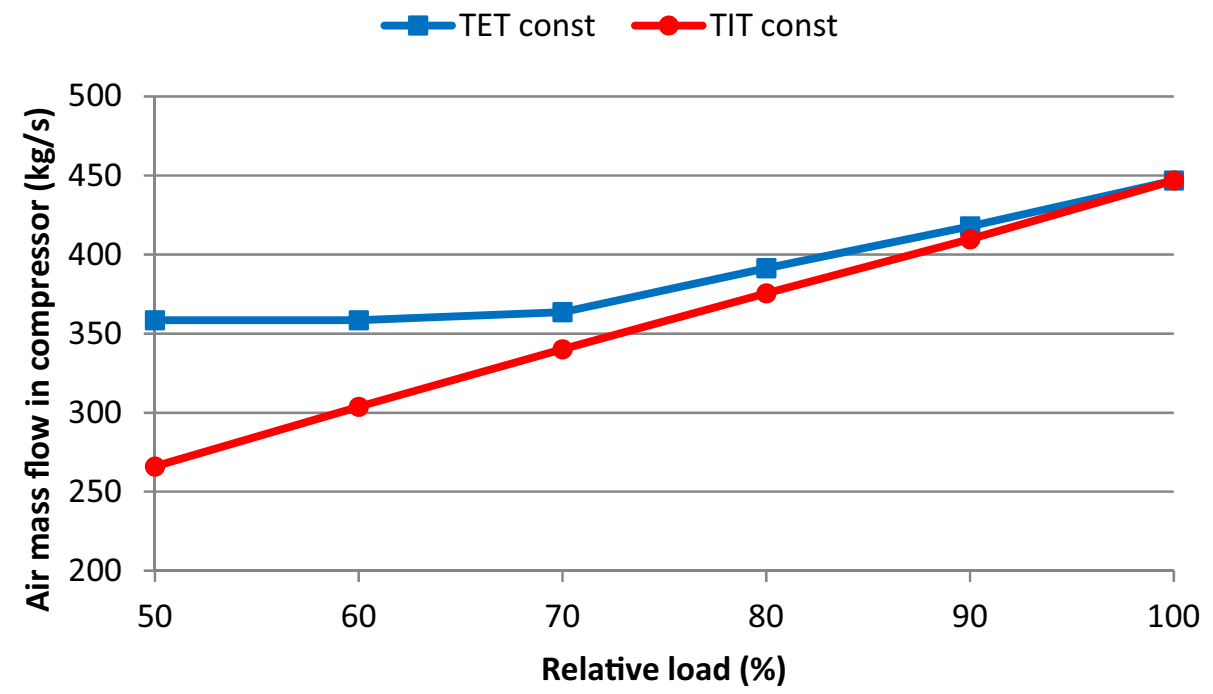

Fig. 4. Variation of compressor air mass flow with relative load.

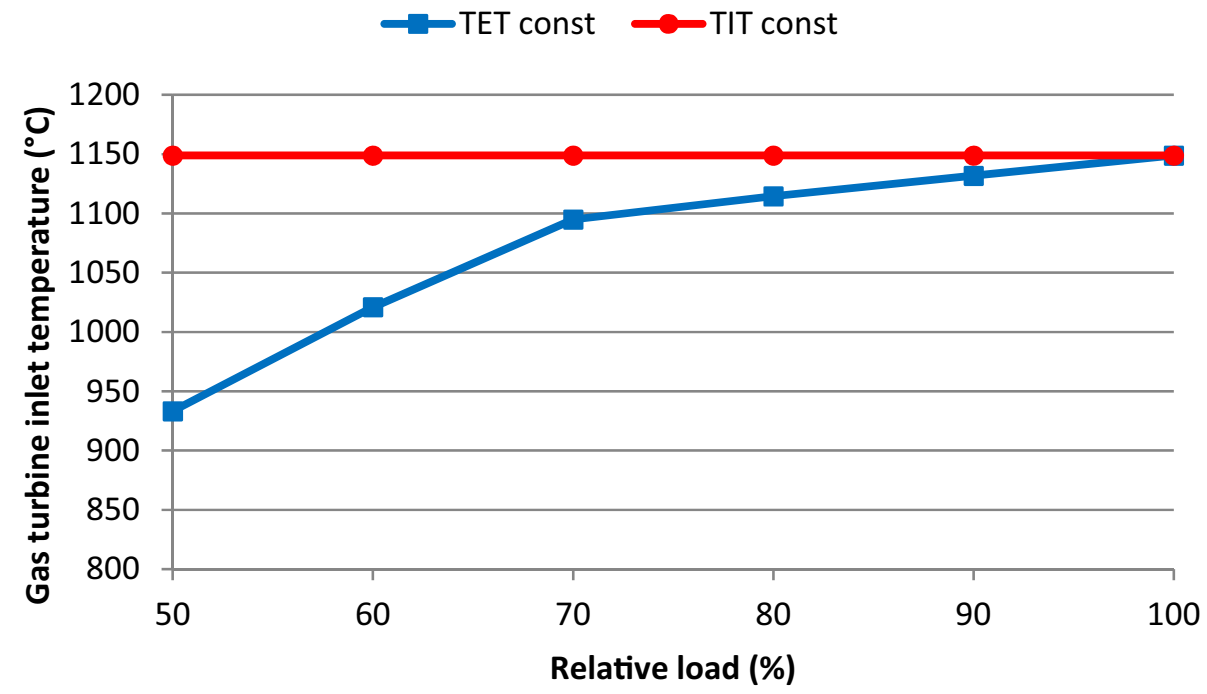

Fig. 5. Variation of gas turbine inlet temperature with relative load.

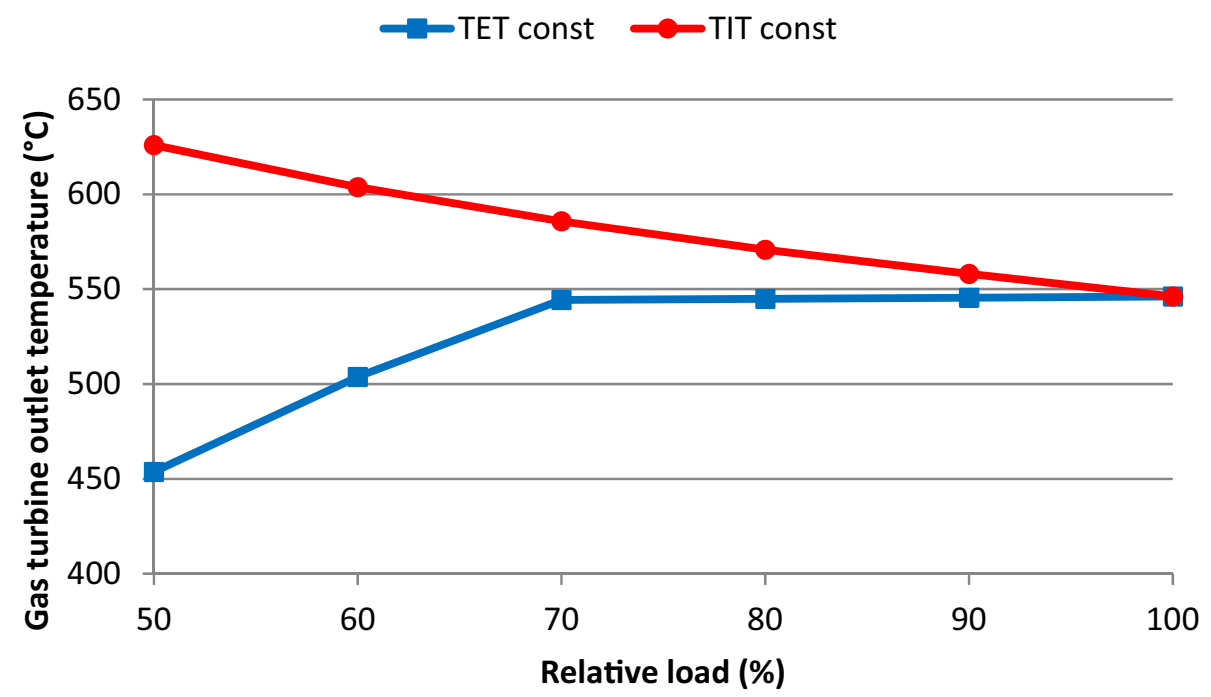

Fig. 6. Variation of gas turbine outlet temperature with relative load. 


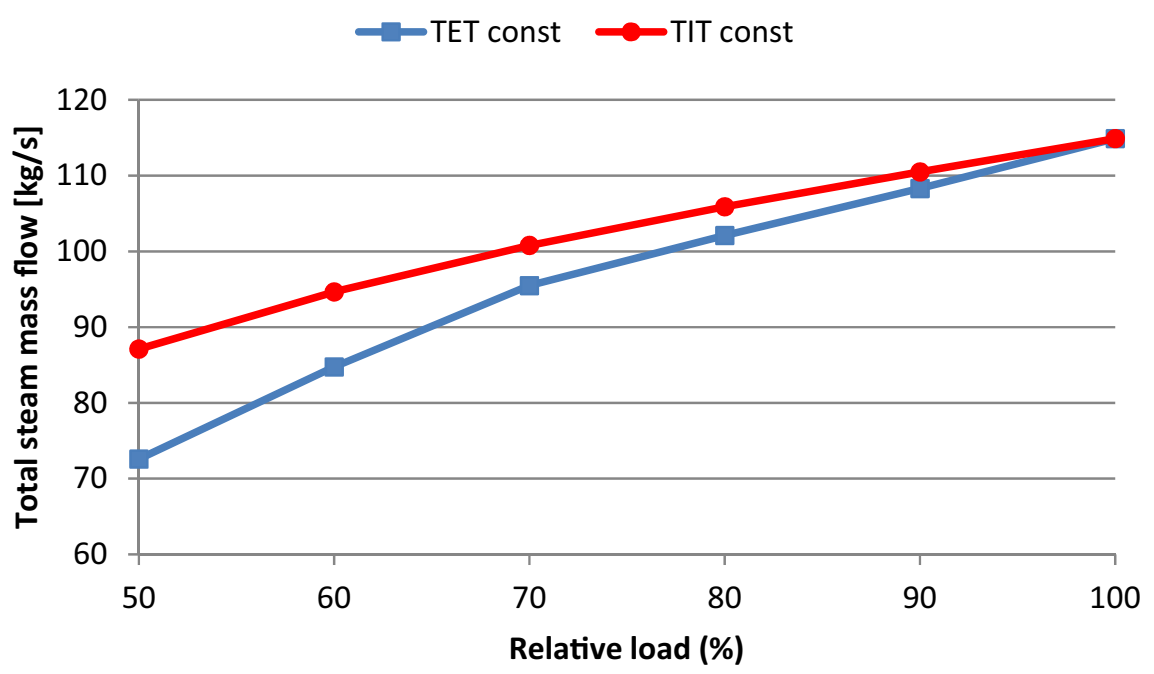

Fig. 7. Reduction of produced steam mass flow with load variation.

Figure 3 shows the variation of fuel mass flow versus relative load. As it could be seen, fuel mass flow rate in both strategies are reduced in a same pattern with load decreasing, but reduction in TET constant mode is a bit higher than TIT constant method.

Unlike fuel mass flow, reduction in air mass flow rate is different in the two selected strategies. When the load is decreased from $100 \%$ to $70 \%$, air mass flow in the compressor reduces linearly in both strategies. The difference occurs between $70 \%$ and $50 \%$ load. In TIT constant mode, reduction in air mass flow continues in the same pattern as before, but in TET constant mode it almost remains constant. In general, with reducing the load form $100 \%$ to $50 \%$, air mass flow in TET and TIT constant modes is decreased by $19.7 \%$ and $40.5 \%$, respectively. Therefore, in TET constant mode a higher amount of air in the combustion chamber is available. Since fuel consumption is approximately similar in the two selected strategies, higher amount of air in TET constant mode leads to lower turbine inlet temperature compared to the TIT constant mode, which its turbine inlet temperature remains constant in part-load operation, as shown in Figure 5.

Another difference between the two strategies is the turbine outlet temperature. As shown in Figure 6, between $100 \%$ and $70 \%$ load, outlet temperature of gas turbine in TET constant mode remains constant, but below the $70 \%$, due to constant amount of air flow, outlet temperature falls and reaches to $450{ }^{\circ} \mathrm{C}$ at $50 \%$ load. Temperature variation of outlet stream of the gas turbine in TIT constant mode is completely different. With decreasing the load, turbine exhaust temperature increases linearly and reaches to $626{ }^{\circ} \mathrm{C}$ at $50 \%$ load. This augmentation could be explained as follows. Turbine outlet temperature is a function of turbine inlet temperature, turbine isentropic efficiency, air specific heat and turbine pressure ratio as shown in Equation (17)

$$
T_{4}=T_{3}\left(1-\eta_{\mathrm{GT}}\left(1-\left(\frac{P_{3}}{P_{4}}\right)^{\frac{1-\gamma_{g}}{\gamma_{g}}}\right)\right)
$$

In the above equation, isentropic efficiency of the turbine is a constant parameter. Also as shown in Figure 5, turbine inlet temperature remains constant and therefore, specific heat of the air which is a function of temperature remains constant. Consequently, in this situation, turbine outlet temperature is only a function of its pressure ratio. Turbine outlet pressure is slightly higher than ambient pressure to overcome the pressure losses in HRSG components and therefore is almost constant. But, turbine inlet pressure reduces in part-load operation due to offdesign performance of the compressor. As a result, turbine pressure ratio is decreased under part-load conditions. With the pressure ratio decreasing and other parameters are being constant, turbine outlet temperature increases, according to Equation (17).

Energy content of the gas turbine outlet stream is used in HRSG to produce steam. With changing mass flow and temperature, its energy content is also changed. This variation affects the HRSG performance by changing the produced steam mass flow and its temperature. Figure 7 shows the amount of total steam mass flow produced in each HRSG using the two strategies. As it could be seen, in TIT constant mode, mass flow of produced steam is higher than TET constant mode. This is because that in TIT constant mode, turbine outlet temperature has higher energy content than TET constant mode, as shown in Figure 6. This also leads to a higher temperature of the produced steam in TIT constant mode as shown in Figure 8. While the temperature of HP steam in TET constant mode is decreased and from $520{ }^{\circ} \mathrm{C}$ in full-load reaches to $447.4^{\circ} \mathrm{C}$ at $50 \%$ load.

With changing the aforementioned parameters, output power of gas and steam turbines along with their energy efficiencies are changed. Table 5 shows output power of the gas turbine, steam turbine and total output power of the cycle in different loads. Also energy efficiency variation is shown in the table. In general, TIT constant mode has higher net output power and energy efficiency. As can be seen, the gas turbine generated power in the two 
A.M. Khoshkar Vandani et al.: Mechanics \& Industry 17, 610 (2016)

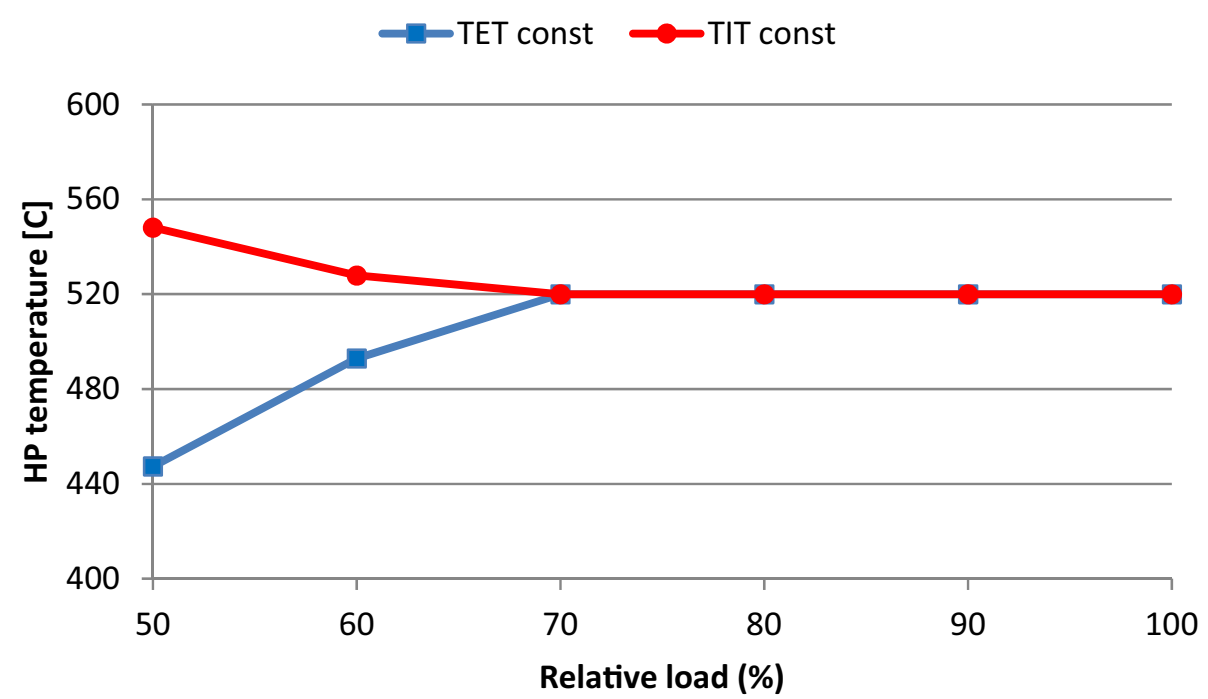

Fig. 8. Variation of HP steam temperature with relative load.

Table 5. Generated power and efficiency of gas turbine, steam turbine and total plant.

\begin{tabular}{|c|c|c|c|c|c|c|c|}
\hline \multirow{2}{*}{ Parameter } & \multirow{2}{*}{ Unit } & \multicolumn{6}{|c|}{ Relative load } \\
\hline & & $50 \%$ & $60 \%$ & $70 \%$ & $80 \%$ & $90 \%$ & $100 \%$ \\
\hline \multicolumn{8}{|c|}{ TET constant mode } \\
\hline Plant gross output & $\mathrm{kW}$ & 207775 & 254772 & 297720 & 331492 & 364476 & 397547 \\
\hline ST gross output & $\mathrm{kW}$ & 70003 & 89507 & 105083 & 111999 & 118315 & 125010 \\
\hline GT gross output & $\mathrm{kW}$ & 68886 & 82632 & 96318 & 109746 & 123080 & 136268 \\
\hline Plant net efficiency & $\%$ & 41.27 & 44.33 & 46.18 & 46.96 & 47.61 & 48 \\
\hline ST net efficiency & $\%$ & 20.46 & 23.21 & 24.56 & 24.27 & 23.96 & 23.62 \\
\hline GT net efficiency & $\%$ & 28.36 & 29.66 & 30.72 & 31.9 & 32.93 & 33.65 \\
\hline \multicolumn{8}{|c|}{ TIT constant mode } \\
\hline Plant gross output & $\mathrm{kW}$ & 239908 & 272388 & 304414 & 336305 & 367360 & 397547 \\
\hline ST gross output & $\mathrm{kW}$ & 100979 & 106303 & 111476 & 116472 & 120882 & 125010 \\
\hline GT gross output & $\mathrm{kW}$ & 69465 & 83042 & 96469 & 109917 & 123239 & 136268 \\
\hline Plant net efficiency & $\%$ & 45.38 & 46.01 & 46.64 & 47.24 & 47.76 & 48 \\
\hline ST net efficiency & $\%$ & 27.54 & 26.43 & 25.6 & 24.94 & 24.32 & 23.62 \\
\hline GT net efficiency & $\%$ & 27.16 & 28.9 & 30.38 & 31.67 & 32.82 & 33.65 \\
\hline
\end{tabular}

strategies are quite alike. The reason for different net output power of the plant is generated power by the steam turbine. As shown in Figures 7 and 8, temperature and mass flow of the produced steam in TIT constant mode is higher than TET constant mode; consequently, steam turbine generated power in TIT constant mode is higher. As revealed in the table, reduction in steam turbine output power in TIT and TET constant modes are $19.22 \%$ and $44 \%$, respectively.

Also beside the higher generated power, TIT constant mode has a higher efficiency in comparison with TET constant mode. When the relative load from 100\% reduces to $50 \%$, the energy efficiency of the plant in TET constant mode from $48 \%$ reaches to $41.27 \%$, while this reduction in TIT constant mode is lower and it reaches to $45.38 \%$. It should be noted that although plant net efficiency in TIT constant mode is higher, but in this strategy, gas turbine efficiency is lower than TET constant mode. The reason behind that is more fuel is consumed in TIT constant mode to keep the turbine inlet temperature at its design point value. Consequently GT efficiency drops in this strategy, but this energy content is recovered in HRSG and therefore, in general, plant net efficiency in TIT constant mode is higher.

As mentioned before, exergy analysis is a better criterion to evaluate the performance of a system. Therefore, in the following, results of exergy analysis are represented. Figure 9 shows variation of plant's total exergy destruction with relative load. As could be seen, with reducing the load, exergy destruction of the plant is decreased. The main reason for reduction of exergy destruction is lower fuel consumption in the combustion chamber. As it is known, combustion chamber has the highest amount of exergy destruction in the plant, due to occurrence of chemical reactions. Therefore with decreasing the fuel consumption, the amount of exergy destruction of the plant decreases. Also, lower amount of air, flue gas and steam is used in the cycle, therefore the exergy destruction is reduces.

Table 6 shows share of each component in exergy destruction of the plant in the two selected strategies. In full-load operation, combustion chamber with $68.76 \%$ has 
A.M. Khoshkar Vandani et al.: Mechanics \& Industry 17, 610 (2016)

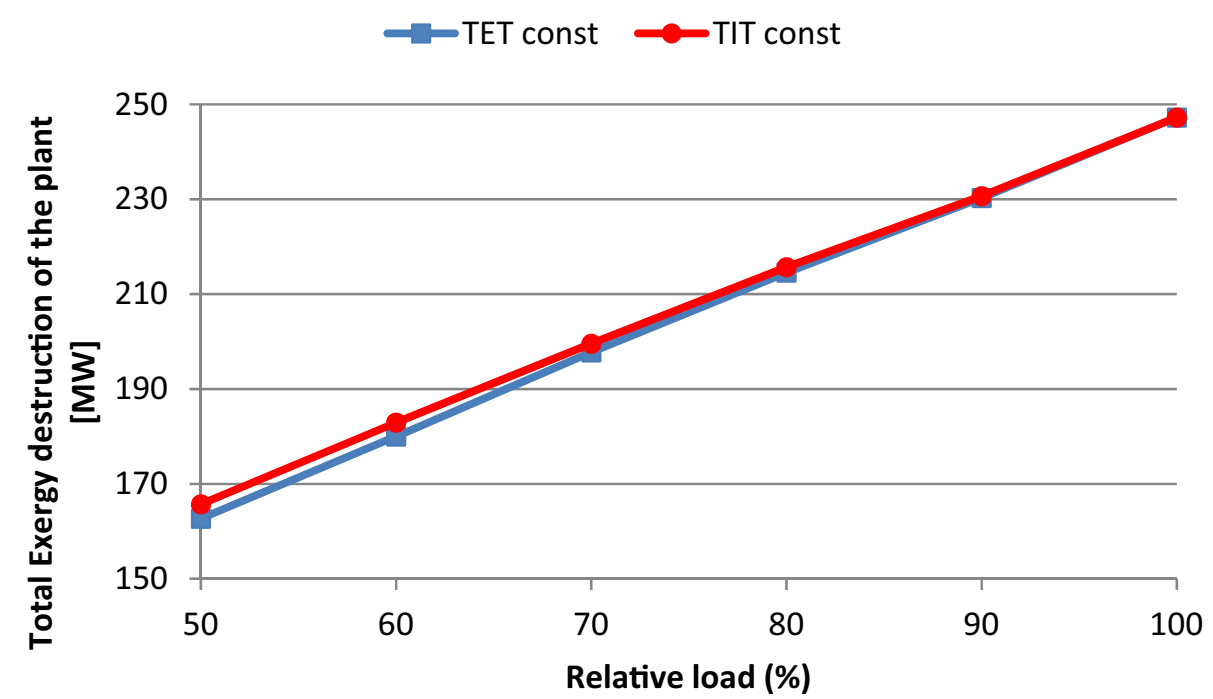

Fig. 9. Variation of plant's total exergy destruction with relative load.

Table 6. Share of each component in total exergy destrucrion.

\begin{tabular}{ccccccc}
\hline Component & \multicolumn{7}{c}{ Relative load } \\
\hline & $50 \%$ & $60 \%$ & $70 \%$ & $80 \%$ & $90 \%$ & $100 \%$ \\
\hline & TET & constant & mode & & & \\
\hline Compressor & 10.11 & 9.23 & 8.51 & 8.06 & 7.60 & 7.50 \\
Combustion chamber & 63.67 & 65.84 & 67.25 & 67.99 & 68.54 & 68.76 \\
Gas Turbine & 7.38 & 5.76 & 4.42 & 4.13 & 3.91 & 3.68 \\
HRSG & 5.28 & 5.26 & 4.98 & 4.87 & 4.83 & 4.82 \\
Steam turbine & 7.23 & 6.34 & 6.17 & 6.05 & 5.93 & 5.81 \\
Condenser & 5.57 & 6.84 & 7.86 & 8.18 & 8.48 & 8.79 \\
Pump & 0.14 & 0.13 & 0.12 & 0.11 & 0.10 & 0.09 \\
Int. Pump & 0.63 & 0.61 & 0.70 & 0.60 & 0.61 & 0.55 \\
\hline Compressor & TIT constant & mode & & & \\
\hline Combustion chamber & 8.27 & 8.34 & 8.21 & 7.90 & 7.54 & 7.50 \\
Gas Turbine & 3.33 & 67.61 & 67.91 & 68.32 & 68.68 & 68.75 \\
HRSG & 5.20 & 5.15 & 3.34 & 3.40 & 3.53 & 3.68 \\
Steam turbine & 6.57 & 6.41 & 6.27 & 4.88 & 4.83 & 4.82 \\
Condenser & 8.04 & 8.38 & 8.56 & 8.68 & 8.77 & 5.81 \\
Pump & 0.14 & 0.13 & 0.12 & 0.11 & 0.10 & 0.09 \\
Int. Pump & 1.30 & 0.68 & 0.65 & 0.61 & 0.57 & 0.55 \\
\hline
\end{tabular}

the highest amount of exergy destruction, followed by condenser, compressor, steam turbine and HRSG. Under part-load conditions, share of exergy destruction in some components, including compressor, HRSG, steam turbine and the pumps, increases. On the other hand, share of exergy destruction in combustion chamber and condenser decreases. It should be noted that gas turbine has different behavior in the two strategies. In TET constant mode, reducing the relative load result in an increase in the exergy destruction share of the gas turbine, while in TIT constant mode, with reducing the load, exergy destruction share of the gas turbine is decreased.

As could be seen in the table, in all relative loads, combustion chamber's share of exergy destruction in TIT constant mode is higher than TET constant mode, due to higher amount of fuel consumption in this strategy (Fig. 3). Also due to higher amount of air mass flow in
TET constant mode (Fig. 4), compressor's share of exergy destruction in TET constant mode is higher than TIT constant mode.

When the load is reduced to $50 \%$, the order of components which have the highest share of exergy destruction is changed. In TET constant mode the highest share of exergy destruction is belonged to combustion chamber, compressor, gas turbine, steam turbine and condenser, respectively. In TIT constant mode, combustion chamber and compressor still has the highest share of exergy destruction. After these two, condenser, steam turbine and HRSG have the highest share.

Figure 10 shows exergy efficiency of the plant under selected part-load strategies. As shown in Figure 3, in TIT constant mode more fuel is consumed. But, instead, more power is generated. In general, TIT constant mode has higher exergy efficiency, both in full-load and part-load 


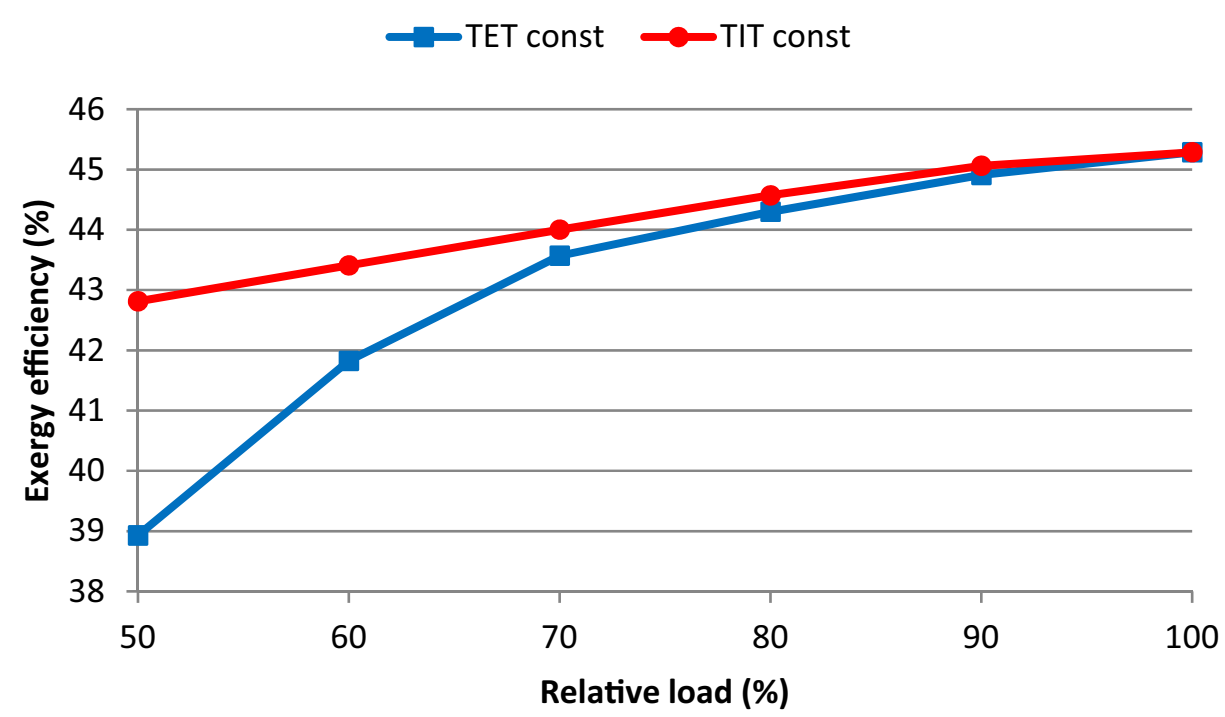

Fig. 10. Exergy efficiency of the plant in part-load operation.

Table 7. Produced emission in part-load operation.

\begin{tabular}{ccccccc}
\hline \multirow{2}{*}{ Contaminants } & 50 & \multicolumn{7}{c}{ Relative load (\%) } \\
\cline { 2 - 7 } & 50 & \multicolumn{7}{c}{70} & 80 & 90 & 100 \\
\hline $\mathrm{CO}\left(\mathrm{kg} \cdot \mathrm{s}^{-1}\right)$ & 0.226491 & 0.187875 & 0.160853 & 0.145043 & 0.133023 & 0.121274 \\
$\mathrm{UHC}\left(\mathrm{kg} . \mathrm{s}^{-1}\right)$ & 0.022645 & 0.017454 & 0.014083 & 0.012284 & 0.010956 & 0.009709 \\
$\mathrm{NO}_{x}\left(\mathrm{~kg} \cdot \mathrm{s}^{-1}\right)$ & 0.002855 & 0.03114 & 0.183514 & 0.274638 & 0.380531 & 0.510463 \\
$\mathrm{CO}_{2}\left(\mathrm{~kg} \cdot \mathrm{s}^{-1}\right)$ & 1375.811 & 1575.805 & 1771.409 & 1943.839 & 2110.881 & 2286.519 \\
\hline \multicolumn{7}{c}{ TIT constant mode } \\
\hline $\mathrm{CO}\left(\mathrm{kg} \cdot \mathrm{s}^{-1}\right)$ & 0.237538 & 0.199928 & 0.167574 & 0.148492 & 0.133495 & 0.121274 \\
$\mathrm{UHC}\left(\mathrm{kg} . \mathrm{s}^{-1}\right)$ & 0.022753 & 0.018297 & 0.014639 & 0.012553 & 0.010965 & 0.009709 \\
$\mathrm{NO}_{x}\left(\mathrm{~kg} \cdot \mathrm{s}^{-1}\right)$ & 0.139031 & 0.190789 & 0.332733 & 0.410867 & 0.486657 & 0.510463 \\
$\mathrm{CO}_{2}\left(\mathrm{~kg} \cdot \mathrm{s}^{-1}\right)$ & 1443.838 & 1622.165 & 1792.588 & 1959.124 & 2120.693 & 2286.519 \\
\hline
\end{tabular}

operation. When the load is reduced, exergy efficiency in TIT constant mode decreases slightly, while load reduction in TET constant mode leads to a sharp decrease in exergy efficiency of the plant. Difference between exergy efficiency of the two selected strategies is more obvious below $70 \%$ load, in a way that in $50 \%$ load, efficiency of these two strategies differs by $3.89 \%$.

As shown, part-load operation of the plant is controlled by changing the thermodynamic conditions, such as air and fuel mass flow rates. These changes lead to different environmental performance of the plant. As could be seen in Equations (9) to (11), adiabatic flame temperature has a dominant effect on the amount of produced contaminants. Since different rates of air and fuel mass flow are used in the two selected strategies, therefore reduction of the adiabatic flame temperature in part-load operation in the two strategies is different. Figure 11 shows this difference in different relative loads. As expected, TIT constant mode has a higher flame temperature in all relative loads. With different flame temperature and different air and mass flow rates, different amount of contaminants will be produced. Table 7 shows how much of each contaminant is produced in part-load operation in the two selected strategies.
As it could be seen, with reducing the relative load, the amount of produced carbon monoxide and UHC are increased. This is because that incomplete combustion is the main source of carbon monoxide and UHC formation and decreasing the relative load increases the chance of incomplete combustion. As a result, the amount of these contaminants increases. Also rate of increase of these pollutants are almost the same in the two strategies.

On the other hand, most $\mathrm{NO}_{x}$ emissions are formed by the effect of high temperature on atmospheric nitrogen. Consequently, the higher the adiabatic flame temperature, the higher the $\mathrm{NO}_{x}$ formation. Since the flame temperature in TIT constant mode is higher, therefore the amount of produced $\mathrm{NO}_{x}$ is higher than the TET constant mode. Also, since in part-load operation lower fuel is burnt, the amount of produced carbon dioxide is decreased.

As shown in Table 7, part-load operation has different effects on the produced emissions. Eco-indicator 99 is used to perform a comprehensive environmental analysis. The considered contaminants, affect three environmental issues, including:

- Damage to Ecosystem Quality caused by the combined effect of acidification and eutrophication. 
A.M. Khoshkar Vandani et al.: Mechanics \& Industry 17, 610 (2016)

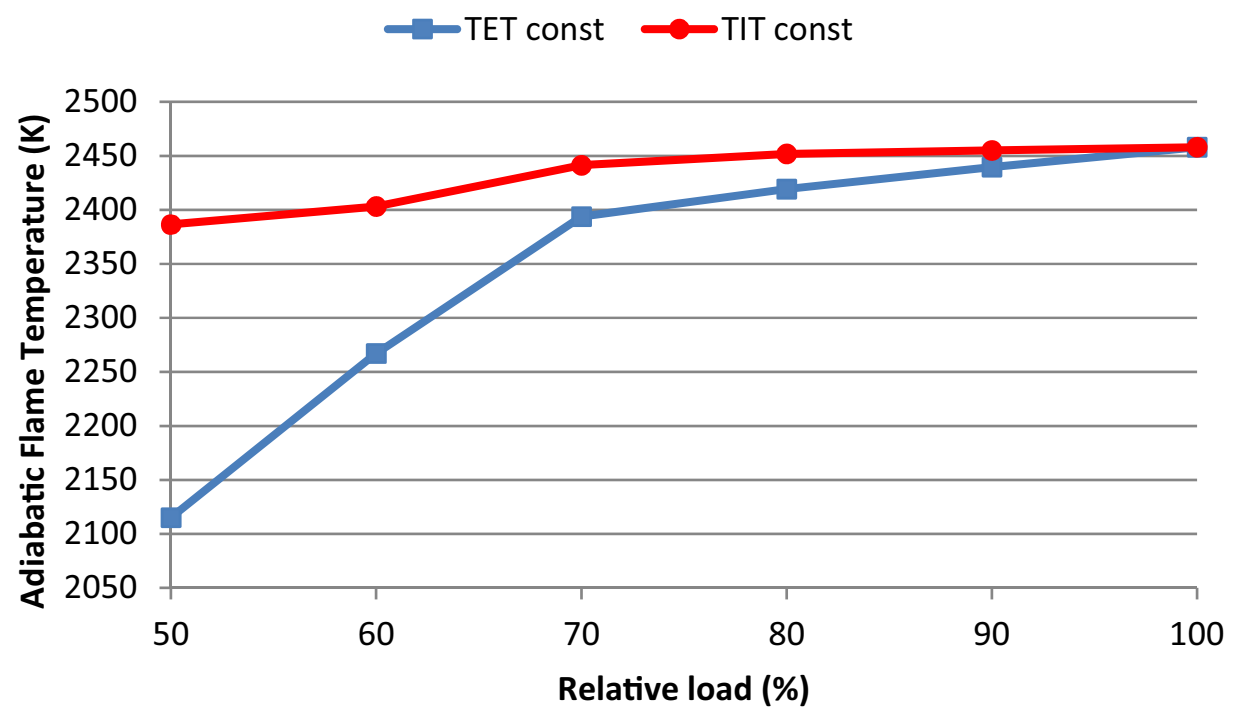

Fig. 11. Adiabatic flame temperature in different relative loads.

Table 8. Results of environmental analysis.

\begin{tabular}{ccccccc}
\hline \multirow{2}{*}{ Environmental issues } & \multicolumn{7}{c}{ Relative load (\%) } \\
\cline { 2 - 7 } & \multicolumn{7}{c}{50} & 60 & 70 & 80 & 90 & 100 \\
\hline TET constant mode & & & \\
\hline Respiratory effect & 0.013147 & 0.143253 & 0.844176 & 1.263345 & 1.75045 & 2.348137 \\
Climate change & 15.00538 & 17.18347 & 19.31433 & 21.19313 & 23.01338 & 24.92734 \\
Acidification and eutrophication & 0.002541 & 0.027714 & 0.163328 & 0.244428 & 0.338673 & 0.454312 \\
Total score & 15.02107 & 17.35444 & 20.32183 & 22.7009 & 25.1025 & 27.72979 \\
\hline \multicolumn{7}{c}{ TIT constant mode } \\
\hline Respiratory effect & 0.639557 & 0.877639 & 1.530582 & 1.889994 & 2.238629 & 2.348137 \\
Climate change & 15.74709 & 17.68919 & 19.54542 & 21.35985 & 23.12034 & 24.92734 \\
Acidification and eutrophication & 0.123738 & 0.169802 & 0.296132 & 0.365671 & 0.433125 & 0.454312 \\
Total score & 16.51039 & 18.73663 & 21.37213 & 23.61552 & 25.7921 & 27.72979 \\
\hline
\end{tabular}

- Damages to human health caused by climate change.

- Respiratory effects on humans.

There is an indicator associated to each of the considered emissions in all the aforementioned environmental issues which are expressed per kg emission. These indicators are normalized and multiplied by the weighting factor. The final results of the environmental analysis are shown in Table 8

As could be seen, total effect of TIT constant mode on the environment is higher than the TET constant mode. In both strategies, climate change has the dominant effect. This could be explained by high amount of produced carbon dioxide (as shown in Table 7). Respiratory effect has the second most importance effect in the environmental analysis. But its effect is far lower than the climate change issue. Finally, acidification and eutrophication has the least effect. Since acidification is a result of $\mathrm{NO}_{x}$ production and the $\mathrm{NO}_{x}$ production in TIT constant mode is higher, therefore, acidification score in TIT constant mode is more than TET constant mode. In general, it could be concluded that TET constant mode is more environmentally friendly.

\section{Conclusion}

In this study, energy, exergy and environmental analyses of a combined cycle power plant under full-load and part-load conditions were evaluated. Part-load operation was applied to the plant using to two different controlling strategies, including constant turbine inlet temperature and constant turbine outlet temperature. Results showed that when TIT constant mode is applied to the plant, higher amount of fuel would be used, but instead generated power is increased. Since in TIT constant mode, turbine outlet temperature increases with load reduction, the outlet flue gas has higher energy content and therefore in this situation more steam is produced in the HRSG. This led to higher generated power in steam turbine. When relative load from $100 \%$ reduces to $50 \%$, energy efficiency of the plant in TET constant mode from $48 \%$ reaches to $41.27 \%$, while this reduction in TIT constant mode is lower and it reaches to $45.38 \%$. In general, TIT constant mode has a better performance than TET constant mode and has a higher generated power and energy efficiency. Also exergy analysis showed that among all components, combustion chamber has the highest rate of exergy destruction, both in full-load and part-load 
operations. When the plant operates at part-load condition, with load reducing, combustion chamber shares of exergy destruction is decreased. Also in part-load operation, total exergy destruction of the plant is decreased which is mainly due to lower fuel consumption. In general, based on the obtained results, it could be said that the performance of the plant in TIT constant mode is better, both in output power and exergy efficiency. Therefore, it is suggested to use this method in part-load conditions.

Unlike the exergetic analysis, environmental analysis results showed that TET constant mode produces lower contaminants. TIT constant mode consumes higher amount of fuel, therefore its carbon dioxide production is higher than TET constant mode. Also since the adiabatic flame temperature is higher in this strategy; higher amount of $\mathrm{NO}_{x}$ will be produced. In general, environmental analysis showed that TET constant mode is more environmentally friendly.

\section{References}

[1] B. Ghorbani, et al., Exergy and exergoeconomic evaluation of gas separation process, J. Natural Gas Sci. Eng. 9 (2012) 86-93

[2] S. Tahmasebi, et al., Investigation of various feed conditions on NGL recovery plant energy and exergy performance: A case study, J. Natural Gas Sci. Eng. 22 (2015) $83-89$

[3] M. Ashouri, F.R. Astaraei, R. Ghasempour, M. Ahmadi, M. Feidt, Thermodynamic and economic evaluation of a small-scale organic Rankine cycle integrated with a concentrating solar collector, Int. J. Low-Carbon Technol. 2015 (2015) 1-12

[4] H. Ganjehsarabi, A. Gungor, I. Dincer, Exergoeconomic evaluation of a geothermal power plant, Int. J. Exergy 14 (2014) 303-319

[5] E. Hajidavalloo, A. Vosough, Energy and exergy analyses of a supercritical power plant, Int. J. Exergy 9 (2011) $435-452$

[6] A.M.K. Vandani, M. Bidi, F. Ahmadi, Exergy analysis and evolutionary optimization of boiler blowdown heat recovery in steam power plants, Energy Convers. Manage. 106 (2015) 1-9

[7] S. Khanmohammadi, A.R. Azimian, S. Khanmohammadi, Exergy and exergo-economic evaluation of Isfahan steam power plant, Int. J. Exergy 12 (2013) 249-272

[8] F. Khaldi, B. Adouane, Energy and exergy analysis of a gas turbine power plant in Algeria, Int. J. Exergy 9 (2011) 399-413

[9] K.C. Kim, J.M. Ha, K.H. Kim, Exergy analysis of a combined power cycle using low-grade heat source and LNG cold energy, Int. J. Exergy 17 (2015) 374-400

[10] P. Ahmadi, I. Dincer, M.A. Rosen, Exergy, exergoeconomic and environmental analyses and evolutionary algorithm based multi-objective optimization of combined cycle power plants, Energy 36 (2011) 5886-5898

[11] Y. Yassi, S. hashemloo, Improvement of the efficiency of the Agnew micro hydro turbine at part loads due to installing guide vanes mechanism, Energy Convers. Manage. 51 (2010) 1970-1975
[12] T.I. Mohamad, H.G. How, Part-load performance and emissions of a spark ignition engine fueled with RON95 and RON97 gasoline: Technical viewpoint on Malaysia's fuel price debate, Energy Convers. Manage. 88 (2014) 928-935

[13] A. Hosseinzadeh, R. Khoshbakhti Saray, S.M. Seyed Mahmoudi, Comparison of thermal, radical and chemical effects of EGR gases using availability analysis in dualfuel engines at part loads, Energy Convers. Manage. 51 (2010) 2321-2329

[14] V. Roeder, A. Kather, Part Load Behaviour of Power Plants with a Retrofitted Post-combustion CO2 Capture Process, Energy Procedia 51 (2014) 207-216

[15] S. Adibhatla, S.C. Kaushik, Energy and exergy analysis of a super critical thermal power plant at various load conditions under constant and pure sliding pressure operation, Appl. Thermal Eng. 73 (2014) 51-65

[16] S.H. Chan, H.K. Ho, Y. Tian, Modelling for part-load operation of solid oxide fuel cell-gas turbine hybrid power plant, J. Power Sources 114 (2003) 213-227

[17] D.P. Bakalis, A.G. Stamatis, Full and part load exergetic analysis of a hybrid micro gas turbine fuel cell system based on existing components, Energy Convers. Manage. 64 (2012) 213-221

[18] W. Rachtan, L. Malinowski, An approximate expression for part-load performance of a microturbine combined heat and power system heat recovery unit, Energy 51 (2013) 146-153

[19] L. Malinowski, M. Lewandowska, Analytical model-based energy and exergy analysis of a gas microturbine at partload operation, Appl. Thermal Eng. 57 (2013) 125-132

[20] W. Wang, R. Cai, N. Zhang, General characteristics of single shaft microturbine set at variable speed operation and its optimization, Appl. Thermal Eng. 24 (2004) 18511863

[21] T.S. Kim, S.H. Hwang, Part load performance analysis of recuperated gas turbines considering engine configuration and operation strategy, Energy 31 (2006) 260-277

[22] T.W. Song, et al., Exergy-based performance analysis of the heavy-duty gas turbine in part-load operating conditions, Exergy, An Int. J. 2 (2002) 105-112

[23] J.M. Muñoz de Escalona, et al., Part-load analysis of gas turbine \& ORC combined cycles, Appl. Thermal Eng. 36 (2012) 63-72

[24] F. Alobaid, et al., A comparative study of different dynamic process simulation codes for combined cycle power plants - Part A: Part loads and off-design operation, Fuel 153 (2015) 692-706

[25] T.S. Kim, Comparative analysis on the part load performance of combined cycle plants considering design performance and power control strategy, Energy 29 (2004) $71-85$

[26] M. Edris, Comparison between single-shaft and mutlishaft gas fired $800 \mathrm{MWel}$ combined cycle power plant, Appl. Thermal Eng. 30 (2010) 2339-2346

[27] T.J. Kotas, The exergy method of thermal plant analysis, Elsevier, 2013

[28] B. Adrian, G. Tsatsaronis, M. Moran, Thermal Design \& optimization. John Willey-Interscience Publication, New York, 1996 
[29] I. Dincer, M.A. Rosen, Exergy: energy, environment and sustainable development, Newnes, 2012

[30] I. Dincer, Y.A. Cengel, Energy, entropy and exergy concepts and their roles in thermal engineering, Entropy 3 (2001) 116-149

[31] ISO 14040, Environmental Management - Life Cycle Assessment - Principles and Framework, International Organization for Standardisation, Geneva, Switzerland, 2006

[32] M. Goedkoop, R. Spriensma, The eco-indicator99: A damage oriented method for life cycle impact assessment: Methodology report, 2001
[33] R. Brunet, et al., Minimization of the LCA impact of thermodynamic cycles using a combined simulationoptimization approach, Appl. Thermal Eng. 48 (2012) $367-377$

[34] K.-M. Lee, S.-Y. Lee, T. Hur, Life cycle inventory analysis for electricity in Korea, Energy 29 (2004) 87-101

[35] R.B. Tan, D. Wijaya, H.H. Khoo, LCI (Life cycle inventory) analysis of fuels and electricity generation in Singapore, Energy 35 (2010) 4910-4916

[36] GTPRO 23, Thermal Engineering Software for the Power Industry, Thermoflow, Inc., USA, 2013 